\title{
Congenital Pseudoaneurysm of the Mitral Aortic Intervalvular Fibrosa in neonatal Marfan syndrome - Transthoracic Echocardiogram and Computed Tomography images
}

Sathish Chikkabyrappa ${ }^{1}$, Kathryn Virk ${ }^{1}$, Mark Castro ${ }^{2}$, Jenna Schauer ${ }^{1}$, Eyal Sagiv ${ }^{1}$, and Sujatha Buddhe ${ }^{1}$

${ }^{1}$ Seattle Children's Hospital

${ }^{2}$ University of Washington Department of Medicine

May 13, 2021

\begin{abstract}
Congenital Pseudoaneurysm of the mitral aortic intervalvular fibrosa (P-MAIVF) is extremely rare condition. We report a case of neonatal Marfan syndrome with unique and rare diagnosis of case of congenital pseudoaneurysm of the mitral aortic intervalvular fibrosa, where the transthoracic echocardiogram and computed tomography images described a congenital pseudoaneurysm of the mitral aortic intervalvular fibrosa.
\end{abstract}

\section{Hosted file}

Aortomitral fibrosa anerysm image report_SB FINAL.pdf available at https://authorea. com/users/413731/articles/521952-congenital-pseudoaneurysm-of-the-mitral-aorticintervalvular-fibrosa-in-neonatal-marfan-syndrome-transthoracic-echocardiogram-andcomputed-tomography-images 

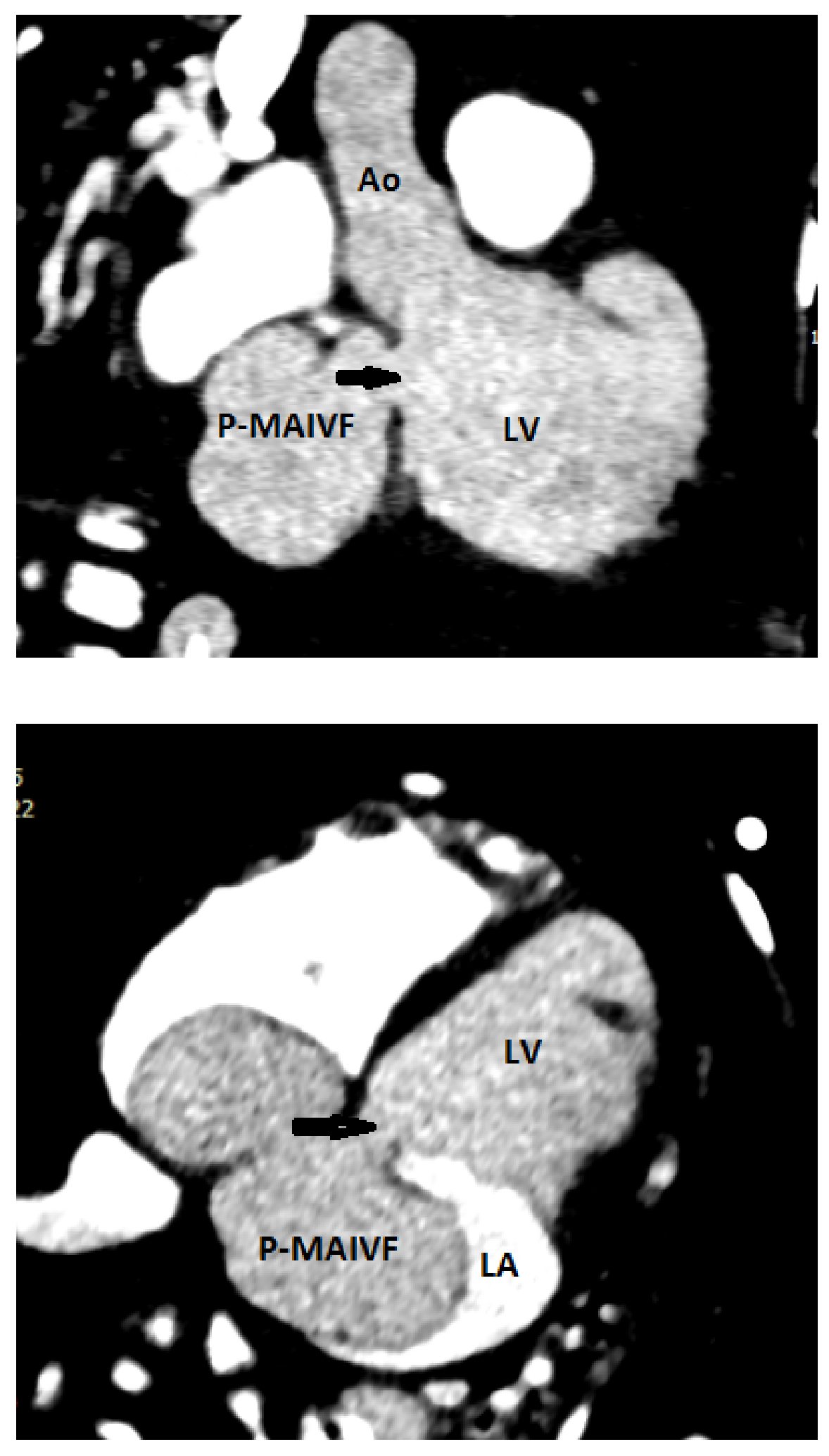

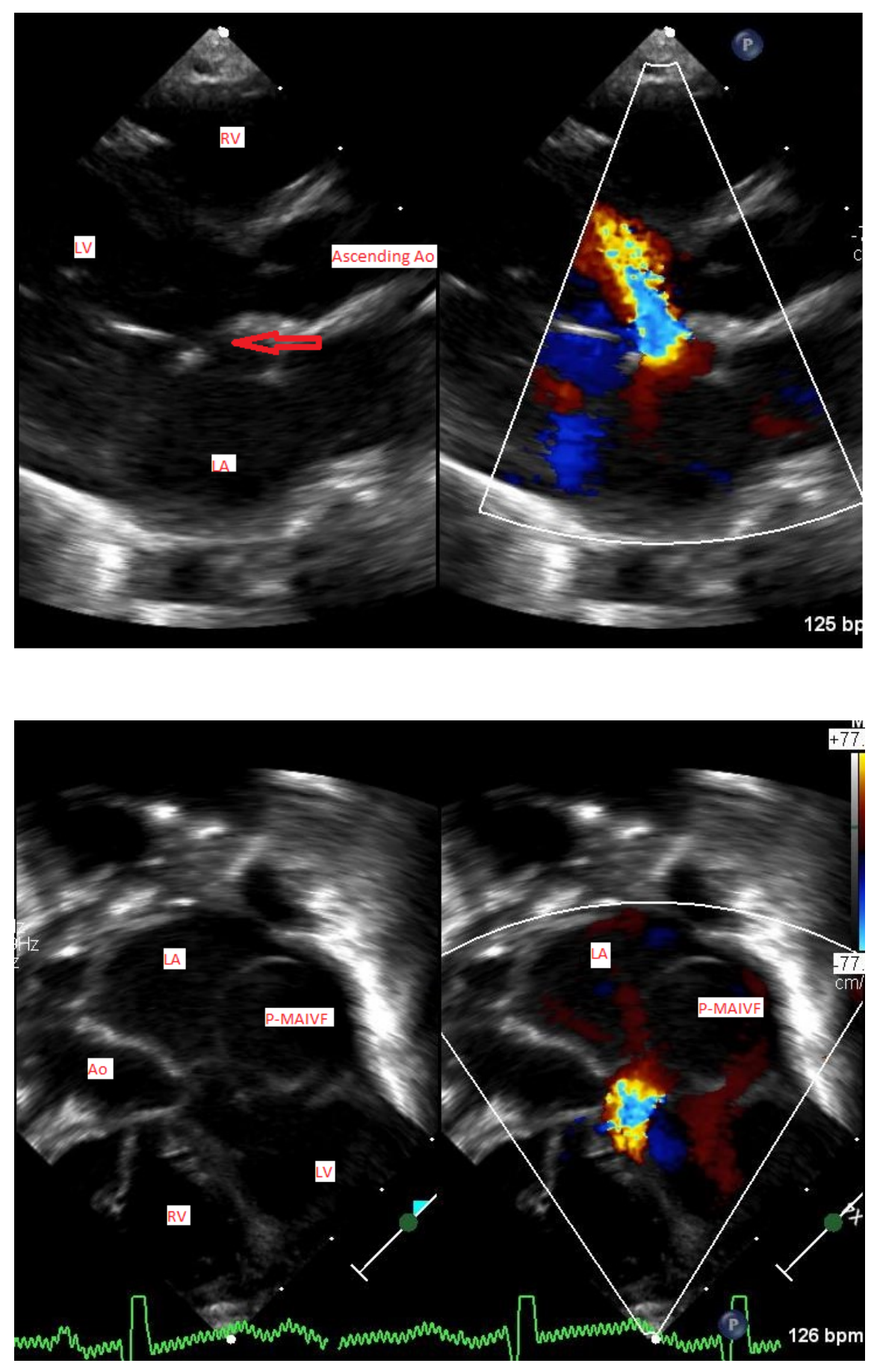


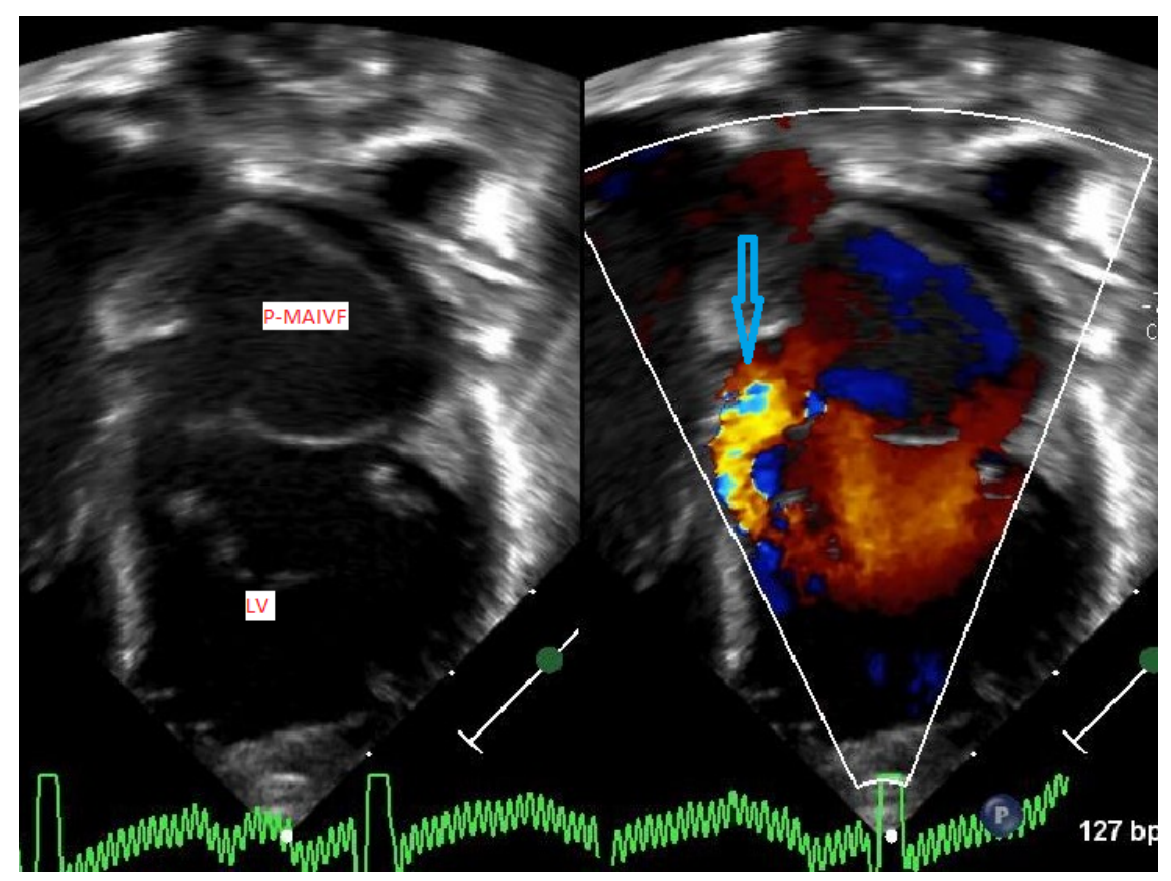

